\title{
Building an e-portfolio learning model: Goal orientation and metacognitive strategies
}

\section{Jeff J.S. Huang}

Department of Computer Science and Information Engineering Hwa Hsia Institute of Technology, Taiwan

E-mail: Jeff@cc.hwh.edu.tw

\section{Stephen J.H. Yang*}

Department of Computer Science \& Information Engineering

National Central University, Taiwan

E-mail: jhyang@csie.ncu.edu.tw

\section{Poky Y.F. Chiang}

Department of Computer Science \& Information Engineering

National Central University, Taiwan

E-mail: pocky1018@gmail.com

\section{Luis S.Y. Tzeng}

Department of Computer Science \& Information Engineering National Central University, Taiwan

E-mail: luistzeng@hotmail.com

*Corresponding author

\begin{abstract}
Recent wide acceptance of e-Portfolios has occurred because researchers believe it helps promote students' learning in higher education. This study uses goal orientation theory to investigate the relationship between goal orientations, metacognitive strategies, and enjoyment when students use ePortfolio. This paper contributes to research by goal orientation, metacognitive strategies and enjoyment to explain student learning behavior when using ePortfolio to providing further evidence. A sample of 219 university students took part in this research to verify the proposed model. The study employs structural equation modeling with the LISREL to explain the model. The results show that students' mastery goals for using e-Portfolio have a positive effect on their metacognitive strategies and enjoyment. Performance-approach goals have a negative effect on metacognitive strategies and a positive effect on enjoyment. Performance-avoidance goals have a positive effect on metacognitive strategies. Students' enjoyment has a positive effect on their metacognitive strategies, and mastery goals can predict metacognitive strategies through enjoyment. This paper also discusses study findings and implications for future research.
\end{abstract}

Keywords: e-Portfolio; Goal orientations; Metacognitive strategies; Performance-avoidance; Self-reflection 
Biographical notes: Jeff J.S. Huang received his $\mathrm{PhD}$ degree in Computer Science and Information Engineering from the National Central University at Taiwan in 2010. He is now an Assistant Professor of the Department of Computer Science and Information Engineering, Hwa Hsia Institute of technology, Taiwan. His research interests include e-Portfolio, e-learning, Web 2.0, CSCW, and CSCL.

Dr. Stephen J.H. Yang is the Distinguished Professor of Computer Science \& Information Engineering, and the Associate Dean of Academic Affairs at the National Central University, Taiwan. Dr. Yang received his $\mathrm{PhD}$ degree in Electrical Engineering \& Computer Science from the University of Illinois at Chicago in 1995. Dr. Yang has published over 60 journal papers, and received the 2010 outstanding research award from National Science Council, Taiwan. His research interests include creative learning, 3D virtual worlds, App software, and cloud services. Dr. Yang is very active in academic services. He is currently the Editors-in-Chief of the International Journal of Knowledge Management \& E-Learning, and the Associate Editor of the International Journal of Systems and Service-Oriented Engineering. Dr. Yang also served as the Program Co-Chair of APTEL 2011, ICCE 2010, TELearn 2009, ICCE 2009 IEEE SUTC2008, ICCE 2008, IEEE ISM2008, SDPS 2008, IEEE W2ME2007, IEEE CAUL2006, and IEEE MSE2003.

Pocky Y. F. Chiang received her M.S. degree in the Institute of Education, National Cheng Kung University in 2009.Her research interests include goal orientations, learning strategies and e-learning.

Luis S.Y. Tzeng is a Ph.D. student in Computer Science and Information Engineering from the National Central University at Taiwan. He received his Master Degree in Department of Computer Science, Clark Atlanta University at Atlanta, USA in 2000. His research interests include e-Learning, Web 2.0, CSCW, and CSCL.

\section{Introduction}

What is an e-Portfolio (electronic portfolio)? An e-Portfolio is a digital electronic platform that stores visual and auditory content (including text, images, video, and sound) to demonstrate competencies and reflections in a field of knowledge to a teacher, a colleague, a professional, or a community. The platform is not only a learning tool to support a variety of pedagogical processes and assessment purposes, but also a private virtual space in a web-based environment. Many researchers have described the "ePortfolio" (Barrett, 2007; Barrett \& Knezek, 2003).

Focus of higher education has been on the electronic portfolio (e-Portfolio). Researchers have recently devoted efforts to explore the functions and learning benefits of e-Portfolio (Abrami \& Barrett, 2005; Lopez-Fernandez \& Rodriguez-Illera, 2009; Walz, 2006; Zellers \& Mudrey, 2007). Five basic functions characterize e-Portfolio: storage, information management, connections, communication, and development. Based on the five functions, the e-Portfolio focuses on multimedia, hypermedia, and communications capabilities for learner to be displayed or published. Moreover, the ease of storage and the accessibility of e-Portfolio enable individuals to demonstrate learning growth over time and amass continuous documentation of learning. The e-Portfolio platform serves as a repository that allows students to upload learning materials about 
their learning process, utilizing e-Portfolio's three broad applications on process, reflection, and assessment (Barrett, 2007; Herner-Patnode, \& Lee, 2009).

Lopez-Fernez and Rodriguez-Illera (2009) implied that the e-Portfolio was valuable as a personal developmental learning tool in their study. Meyer, Abrami, Wade, Aslan, and Deault (2010) indicated the positive effects of teaching with ePEARL (an electronic portfolio software for supporting self-regulated learning) on students' literacy and self-regulated learning skills. Moreover, researchers have emphasized that e-Portfolio can support students' learning and knowledge construction, and even self-regulated ability (Meyer, Abrami, Wade, Aslan, \& Deault, 2010; Wade, Abrami, \& Sclater, 2005). E-Portfolio not only acts as a multimedia container, but also supports self-regulation and core educational competencies (Abrami \& Barrett, 2005). That is, e-Portfolio is not merely a platform for storing, sharing, and communicating, but also a personal online learning space for learners' reflection, and knowledge construction to enhance learning.

According to Pintrich (2000), review of self-regulated learning research indicates that learners in self-regulated learning components include order cognition, motivation / emotion, behavior and context in the self-study course. One cognitive component refers to cognitive strategies and metacognitive strategies of these two parts. In fact, selfregulated learning strategy contains a motivated learning and metacognitive strategy. Moreover, the past research indicates that the relationship between e-Portfolio and metacognitive strategies is positive (Azevedo, 2005; Zellers \& Mudrey, 2007). Zellers and Mudrey (2007) indicate that e-portfolios can be an effective platform for students to increase metacognition. Therefore, this study focuses on the metacognitive strategy of self-regulated learning strategy to develop variety metacognitive strategy in the ePortfolio platform.

As far as the metacognitive strategies are concerned, it is said that their self learning process to demonstrate self ability about showed on the planning strategic, monitoring, correction of ability. Planning strategic which refers to learners before learning goals set for themselves to learn the steps and planning thinking and behavior. Monitoring strategies that learners in learning through self-reflection of the steps or methods, based on the progress to understand their future, and to grasp the meaning of the reflection problem. It can be considered as a kind of self-reflection thinking of the qualification process. Correction strategies help students regulate their own learning skills depending on the level of learning materials and learning status of students during the learning processes.

Using e-Portfolio in education should help learners to aware of their own thinking, to reflect their thinking and to direct their motivation toward valuable goals. Furthermore, the self-regulated learning theory (or self-regulation) refers to the process in which learners methodically activate and sustain cognitions, affects, and behaviors toward the attainment of learning goals (Zimmerman, 2001). Based on the theory, we apply the ePortfolio learning platform to help student to realize the setting goal, planning ahead, content monitoring, planning during writing, checking and correcting. In the e-Portfolio learning process, self-regulated students tend to use learning strategies to metacognitively, motivationally, and behaviorally regulate and promote their performance. In fact, among self-regulated learning strategies, metacognitive strategies relate best to the capabilities of e-Portfolio. Meyer, Abrami, Wade, Aslan, and Deault (2010) pointed out that teaching with e-Portfolio has positive impacts on students' self-regulated learning skills because ePortfolio is learner-centered and scaffolds students' metacognitive strategies. Besides, Artino (2009) indicated that contextual features of the learning environment affect students' motivational beliefs, and these beliefs influence academic emotions, such as 
enjoyment, as well as facilitate using metacognitive strategies. For this reason, this study uses goal orientation theory to investigate the relationship between goal orientations and metacognitive strategies when students use e-Portfolio. In addition, we have take into consideration the enjoyment to understand academic emotions. This paper infers that the features of e-Portfolio, with its emphasis on the learning process and learner-centered learning, may affect students' motivational beliefs, academic emotions, and metacognitive strategies differently than the traditional classroom.

Moreover, according to Blackburn and Hakel (2006), e-Portfolio not only fosters self-regulated learning, but also serves as a framework for including a more effective goal orientation. Among the theories concerning motivational belief, researchers in educational psychology have recently shown increased interest in goal orientation theory, an important theory to explain individuals' motivation and achievement behaviors (Elliot \& McGregor, 2001). Goal orientation theory focuses on explaining differences among students in achievement motivation, and posits that learners do academic tasks for diverse purposes. This diversity of reasons contributes to different leaning outcomes (Midgley \& Urdan, 2001; Pintrich, 2000; Urdan, 2004). Goal orientation theory emphasizes the reasons or purposes why individuals learn. These reasons influence individuals' learning performance.

Among students' academic emotions, educational settings have largely neglected enjoyment, compared to anxiety or test anxiety (Pekrun, Goetz, Titz, \& Perry, 2002; Pekrun, 2005; Pekrun, Elliot, \& Maier, 2009). The educational settings are classroom environment, classroom atmosphere and so on. However, students' emotion base on the different educational settings to respond to different climate in the classroom (Pekrun, 2006). Some research (Davis, Bagozzi, \& Warshaw, 1992; Yi \& Hwang, 2003) regarding online learning has found that positive emotions, like enjoyment, are crucial indicators among learning variables and are an important affective antecedents of a user's cognitive behavior (Sahin \& Shelley, 2008). Therefore, this study especially emphasizes enjoyment to investigate its relationship between goal orientations and metacognitive strategies in the e-Portfolio environment.

Previous studies (Artino, 2009; Pekrun, 2006) indicate that contextual features of the learning environment affect students' motivational beliefs, and these beliefs influence discrete achievement emotions as well as facilitate the use of various metacognitive strategies of self-regulated learning in the traditional classroom. However, the researchers do not conduct their studies in the traditional classroom where learning is teachercentered compared to e-Portfolio, which is student-centered. In addition, past studies analyzed variables separately, not by structural equation modeling. Moverover, Structural equation modeling is used for path analysis, factor analysis, regression analysis, while overcoming the past can not be estimated linear statistical shortcomings of the residual measurement error and thus gradually by social science research attention. In addition, we design the learning context of e-Portfolio, exploring students' goal orientations, which are one kind of motivational beliefs, enjoyment, and metacognitive strategies in an integral and complete way. Therefore, this study builds a model and applies goal orientation theory to accomplish the following research purposes:

1. The proposed model can empirically support the collected data in the context of using e-Portfolio.

2. In the context of using e-Portfolio, goal orientations can directly predict enjoyment and metacognitive strategies, enjoyment can directly predict metacognitive strategies, and goal orientations can indirectly predict metacognitive strategies through enjoyment. 
The organization of the paper is as follows: The first Section (Theoretical Framework) presents the functionalities of e-Portfolio and a theoretical and empirical review of achievement goal theory, metacognitive strategies, and enjoyment. The second section (Research Model and Hypotheses) proposes a theoretical model and research hypotheses. The third section (Research method) describes the research method of this study, and the fourth section (Data Analysis and Results) presents the results and data analysis by structural equation modeling (SEM). The fifth section (Discussion) discusses the findings of this study and implications for future researches. Finally, section seven presents the conclusion.

Whatever the reason may be, companies do not successfully manipulate knowledge assets, the case study provides examples of good practices. We detail a case study of one large multi-national consumer product company and dissect the knowledge manipulation activities in its implementation of a Lean Sigma program.

The remainder of the paper is organized as follows. Section 2 briefly describes the case study company and its implementation of a Lean Sigma program. Section 3 examines the five knowledge manipulation activities as they relate to the case study company. Section 4 then examines the four managerial influences as they relate to the case study company. Finally, Section 5 concludes the paper with a discussion of its contributions, limitations, and potential future research.

\section{Theoretical framework: The lean sigma program in a multi-national consumer product company}

\subsection{Goal orientations and e-portfolio}

Traditional goal orientation theory has two primary orientations, mastery goals, and performance goals. Mastery goals seek to increase competence, master academic tasks, and increase skills. Performance goals demonstrate ability, focus on social comparisons of competence, and help the student act intelligently. (Elliot \& Church, 1997; Pintrich, 2000; Wolters, 2004). Thus, Dweck (1986) regards mastery goals as adaptive motivation orientation and performance goals as maladaptive motivation orientation.

However, in empirical examinations of this framework, performance goals were not consistently associated with maladaptive outcomes, and researchers divide performance goals into approach and avoidance components (Elliot \& Church, 1997; Midgley, Kaplan, \& Middleton, 2001). Mastery goals remain the same, while performance goals are divided into performance-approach goals and performanceavoidance goals. According to Pintrich (2000), an approach orientation focuses on the possibility of success and an avoidance orientation focuses on the possibility of failure. Mastery goals refer to engagement with an orientation toward increasing competence. Performance-approach goals refer to orientation engagement toward demonstrating high ability, whereas performance-avoidance goals refer to engagement with an orientation to avoid demonstrating low ability.

Bekele (2010) suggests that a good e-learning setting enhances learning motivation. Since e-Portfolio and goal orientations have received little research, this study explores students' goal orientations in the context of e-Portfolio. Previous studies attempted to investigate the relationship between e-Portfolio and motivation beliefs (Abrami \& Barrett, 2005; Lopez-Fernandez \& Rodriguez-Illera, 2009). For example, Lopez-Fernandez and Rodriguez-Illera (2009) mentioned that the use of a digital learner 
course portfolio has a positive influence on university students' motivation beliefs. Yet, studies concerning e-Portfolio and goal orientation, one kind of motivation belief, are still sparse. However, those few empirical studies (Blackburn \& Hakel, 2006; Matuga, 2009) concerning students' goal orientation in the context of e-Portfolio only investigate mastery goals and performance goals, not the trichotomy of goal orientations. Accordingly, the current study uses goal orientation theory as its basis and divides goal orientation into mastery goals, performance-approach goals, and performance-avoidance goals for examining students' learning process utilizing of e-Portfolio.

\subsection{Metacognitive strategies, enjoyment, and e-portfolio}

According to Wade, Abrami, and Sclater (2005), e-Portfolio connects to a student's ability to self-regulate their learning and improve their meaningful learning of essential skills. Self-regulated learners are individuals who metacognitively, motivationally, and behaviorally participate in their own learning (Zimmerman, 2000). Metacognitive strategies, a main feature of self-regulated learning (SRL), reflect knowledge of one's thinking and the regulation of one's cognition (Tsai, 2009; Sperling, Howard, Staley, \& DuBois, 2004; Zimmerman, 2001). Metacognitive strategies include three general types of strategies: planning, monitoring, and regulating. Planning includes activities such as setting goals for studying, skimming a text before reading, and generating questions before reading a text. These activities seem to help students plan their use of cognitive strategies, activate prior knowledge, and organize and comprehend materials. Monitoring activities include paying attention when reading a text and monitoring comprehension of a lecture. These various monitoring strategies alert students to repair their comprehension by using regulation strategies. Regulation strategies closely connect to monitoring strategies. The monitoring process suggests the need for regulation processes to bring behavior back in line with the goal or to come closer to the criterion (Pintrich, 1999). Presumably, all these metacognitive strategies improve learning by helping students correct their studying behavior and repair deficits in their understanding.

Past research indicates that the relationship between e-Portfolio and metacognitive strategies is positive (Azevedo, 2005; Zellers \& Mudrey, 2007). Zellers and Mudrey (2007) indicate that electronic portfolios can be an effective platform for students to increase metacognition in a community college setting. However, Wickersham and Chambers (2006) found that after a semester of implementation, students still regarded e-Portfolio as an external component for their academic study and even a barrier due to poor technology. Thus, results are ambiguous concerning the relationship between e-Portfolio and metacognitive strategies requiring additional empirical studies to resolve this ambiguity.

Students' academic emotions, other than anxiety, have largely been neglected and relatively few studies have focused on positive emotions like the enjoyment experienced in educational settings (Pekrun et al., 2002; Pekrun, 2005; Pekrun, Elliot, \& Maier, 2009). Research (Davis, Bagozzi, \& Warshaw, 1992; Yi \& Hwang, 2003) regarding online learning has found that positive emotions like enjoyment are crucial indicators of learning variables. Enjoyment is an important affective antecedent of a user's cognitive behavior (Gomez, Wu, \& Passerini, 2010; Shen, Wang, \& Shen, 2009). Davis, Bagozzi, and Warshaw (1992), define enjoyment as the extent to which learners perceive learning activity to be pleasant and satisfactory. Gomez, Wu, and Passerini (2010) regard enjoyment as the positive affect learners feel when their learning experience is pleasurable. Higher perceived enjoyment of the learning experience leads to deeper learning. However, so far, no empirical studies have attempted to investigate students' 
enjoyment when using e-Portfolio. Therefore, this study focuses on analyzing students' enjoyment when using e-Portfolio.

\section{Research model and hypotheses}

\subsection{Research model}

Using e-Portfolio in education should help students' ability to set learning goal and planning in advance, aware of their own thinking, to be use of metacognitive strategies and to direct their motivation toward valuable goals. As far as the majorly functionalities of e-Portfolio platform are learning tree, course discussion, social network, dynamic resume and learning axis. In learning tree functionality, its special feature provides the students setting goal and planning ahead ability to develop. Moreover, it keeps a record of student's creations and works, also provides concrete evidence of student's accumulation of abilities and skills. In course discussion part, its feature provides the students self-reflection and checking and correcting ability to develop. In social network part, it feature can provide students to increase metacognition in a community college setting. In dynamic resume part, it feature can provide learners with the learning process of self-learning and professional competence to develop to accomplish goal.

Although goal orientation, enjoyment, and metacognitive strategies are crucial indicators of students' learning in the traditional classroom, very little empirical research has examined these variables simultaneously in the environment of e-Portfolio, which includes certain features that benefit the learning process, compared to traditional classrooms. Therefore, this study uses goal orientation theory to explain students' goal orientations, enjoyment, and metacognitive strategies while using e-Portfolio. This study proposes that students' goal orientations have a close relationship with metacognitive strategies and enjoyment. Students' metacognitive strategies are also highly related to enjoyment. Students' goal orientations can predict their metacognitive strategies and enjoyment, and enjoyment can predict users' metacognitive strategies in the context of using e-Portfolio.

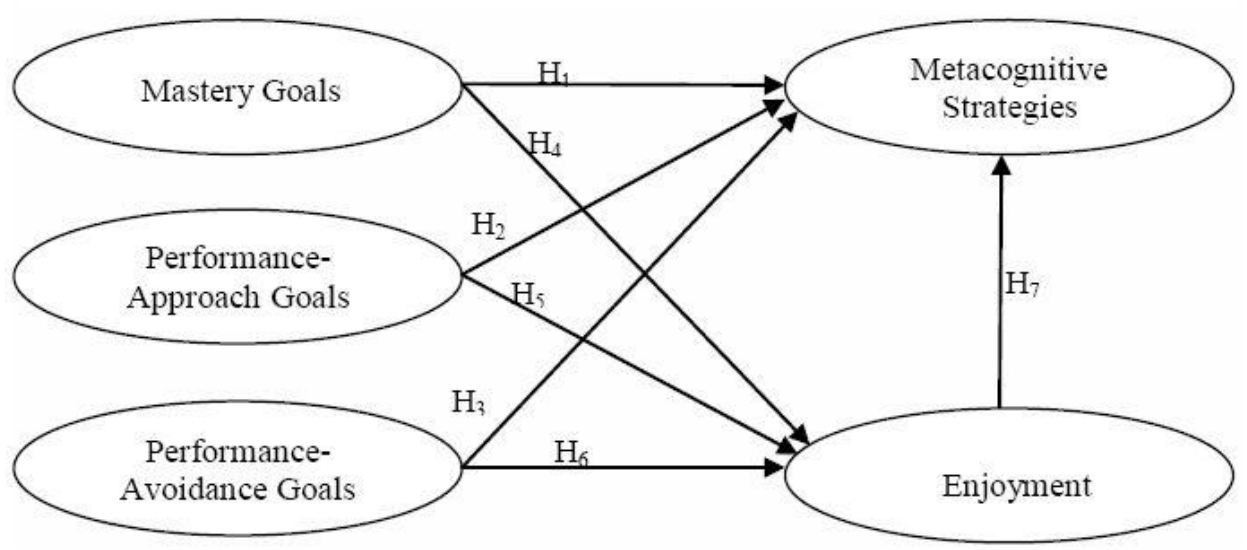

Fig. 1. Proposed research model 
This investigation developed its research model based on information from previous research. Fig. 1 shows the theoretical model for testing and analysis in the context of using e-Portfolio. The direction of arrows links and specifies the hypothesized causal relationships between each construct (latent variables).

\subsection{Hypotheses}

An important assumption in goal orientation theory is that mastery goals, reflecting their desire to increase competence and skills, are the most adaptive patterns of learning among motivation orientations. Performance-avoidance goals, which refer to avoiding demonstration of low ability, are the less adaptive motivation orientations (Dweck, 1986; Kaplan, Lichtinger, \& Gorodetsky, 2009; Witkow \& Fuligni, 2007). Many empirical studies have found that mastery goals have positive effects on deep learning strategies as metacognitive strategies (Bartels \& Magun-Jackson, 2009; Elliot \& McGregor 2001), and performance-avoidance goals have a negative effect on metacognitive strategies (Hou, 2002; Wolters, 2004). Based on these findings, this study assumes that mastery goals can positively predict metacognitive strategies, and performance-avoidance goals can negatively predict metacognitive strategies. However, previous study results concerning performance-approach goals and metacognitive strategies are not consistent and show both positive and negative effects (Vrugt \& Oort, 2008; Wolters, 2004). Some research (Sperling et al., 2004) shows that students' performance-approach goals have a negative effect on their metacognitive strategies. Students with performance-approach goals may demonstrate their ability to manipulate e-Portfolio to their social network and overlook using metacognitive strategies, that is, deep learning strategies. Accordingly, this work predicts that students' performance-approach goals have a negative effect on their metacognitive strategies in the context of using e-Portfolio. From the reviewed literature above, the following hypotheses are proposed:

- Hypothesis 1. When using e-Portfolio, students' mastery goals have a positive effect on their metacognitive strategies.

- Hypothesis 2. When using e-Portfolio, students' performance-approach goals have a negative effect on their metacognitive strategies.

- Hypothesis 3. When using e-Portfolio, students' performance-avoidance goals have a negative effect on their metacognitive strategies.

Pekrun, Elliot, \& Maier (2009) identified and used mastery, performanceapproach, and performance-avoidance goals to predict discrete achievement emotions as enjoyment. Linnenbrink and Pintrich (2002) showed that both mastery and performanceapproach goals seem to predict increased positive emotions when working on academic tasks; performance-avoidance goals relate to anxiety when students can not avoid the outcomes they wish to avoid. Hou (2002) pointed out that performance-avoidance goals have a negative effect on positive emotion. The evidence suggests that students with performance-approach goals may increase positive emotions (Linnenbrink, 2005; Linnenbrink \& Pintrich, 2002), albeit, the results for performance-approach goals are rather mixed. Apparently, students with performance-approach goals feel more enjoyment when using e-Portfolio because they can use e-Portfolio to express themselves. From these reviewed literatures, the following hypotheses are proposed:

$\checkmark$ Hypothesis 4. When using e-Portfolio, students' mastery goals have a positive effect on their enjoyment.

$\checkmark$ Hypothesis 5. When using e-Portfolio, students' performance-approach goals have 
a positive effect on their enjoyment.

- Hypothesis 6. When using e-Portfolio, students' performance-avoidance goals have a negative effect on their enjoyment.

- Hypothesis 7. Students' enjoyment of using e-Portfolio has a positive effect on their metacognitive strategies.

Results from Pekrun et al. (2002) show that positive emotion has a positive relationship with metacognitive strategies and critical thinking. Artino (2009) indicates that achievement emotions, such as enjoyment, relate to the use of self-regulated learning strategies in online courses.

\section{Research method}

\subsection{Participants and procedure}

The participants in the study consisted of 219 undergraduate students taking literacy courses using e-Portfolio in the second semester of 2009. According to Hair, Black, Babin, Anderson, and Tatham (2006), the number of sample should typically be more than 150 and less than 400. Considering the number of parameter estimates and the statements, the number of sample was set to be 300, fifty per cent of the 600 students taking literacy courses. After deciding the number of sample, a cluster sampling method was adopted to choose literacy courses using e-Portfolio after eight weeks. Eight courses were randomly selected from the 12 literacy courses. Three hundred questionnaires were distributed to the students. This study received 219 usable questionnaires out of 244, including $66 \%$ male and $34 \%$ female yielding a response rate of $73 \%$.

\subsection{Instruments}

To achieve the purposes of this study instrument refer to the relate literature and existing theories and measurement tools for the preparation of self measurement tool to collect data coming test of the hypotheses. This study used paper-based questionnaires to collect data. In this study, the study included goal orientation scale, metacognitive strategies scale, enjoyment scale, the following description of the sub-state.

(1) Goal orientations:

Goal orientation scale was Kaplan, Lichtinger, and Gorodetsky (2009) refer to Midgley et al. (2000), adaptive patterns of learning (Patterns of Adaptive Learning Survey, PALS) of the approach performance goals, tend to avoid mastery goals and performance objectives. Writing the original scale to specific fields, this study will guide the personal learning activities to use e-Portfolio for the curriculum to meet the needs of this study, used to measure the personal goal-oriented students.

Personal mastery goals ( 5 items, $\alpha=89$ ), personal performance-approach goals ( 5 items, $\alpha=.90$ ), personal performance-avoidance goals ( 4 items, $\alpha=.79$ ) were assessed with scales adopted from Kaplan, Lichtinger, and Gorodetsky (2009). The Cronbach $\alpha$ reliability estimates from our data were $.95, .95$, and .90 , respectively, for the three types of goals. 


\section{(2)Metacognitive Strategies:}

In this study, we adapted the metacognitive strategies scale of the Kaplan, Lichtinger, and Gorodetsky (2009) to measure the students to use ePortfolios to attend courses of metacognitive strategies scale. Metacognitive strategy is Kaplan, Lichtinger, and Gorodetsky (2009) reference Lichtinger, Kaplan, and Gorodetsky (2006) Writing strategies of self-adjustment scale compiled. The original metacognitive scale in the factor analysis, is divided into the 14 strategies, 64 items, including cognitive strategies, metacognitive strategies and motivation strategies. In this study, we only reference to the subsequent scale of metacognitive strategies. The subsequent scale of metacognitive strategies includes that planning ahead, content monitoring, planning during writing, checking and correcting.

Four main constructs (planning ahead for using e-Portfolio (3 items, $\alpha=.72$ ), content monitoring ( 3 items, $\alpha=.66$ ), planning during writing ( 3 items, $\alpha=.60$ ), and checking and correcting ( 5 items, $\alpha=.90)$ ) were assessed with scales adopted from Kaplan, Lichtinger, and Gorodetsky (2009). The Cronbach $\alpha$ reliability estimates from our data were .91 for all metacognitive strategies constructs.

\section{(3)Enjoyment:}

In this study, we adapted enjoyment scale of the Yi and Hwang (2003) to measure the students to use ePortfolios to attend courses perceived the enjoyment. Enjoyment ( 3 items, $\alpha=.95, .91, .96)$ was measured with 3 items adopted from Yi and Hwang (2003). The Cronbach $\alpha$ reliability estimate from our data was .97.

In this study, the scales above were translated into Chinese and items were modified and phrased to focus on the context using e-Portfolio. The original scale fits the domain-specific context. Each question required participants to select from a Likert-scale ranging from 1 (strongly disagree) to 7 (strongly agree).

\subsection{Learning environment}

As Fig. 2 shows, an e-Portfolio platform that freshman or sophomore has been used for years in the university with more than two thousand registered users, half of whom actively use it (http://www.oaa.ncu.edu.tw/ep/). This e-Portfolio platform was based on goal orientations and metacognitive strategies of self-regulated theory (Zimmerman, 2001) with the purpose of enhancing students' abilities of setting goal, planning ahead, selfmonitoring, self-reflection, checking and correcting. Below are some major functionalities of this e-Portfolio platform:

- Learning tree: Keeps a record of student's creations and works, along with the time axis to observe students' process of knowledge construction; also provides concrete evidence of student's accumulation of abilities and skills. This feature provides the students setting goal and planning ahead ability to develop.

- Course discussion: Provides interaction and sharing of students' reflection of learning through course discussion. This feature provides the students selfreflection and checking and correcting ability to develop.

- Social network: Manages a social network through Facebook to share and disseminate knowledge (Su, Yang, Hwang, \& Zhang, 2010); can automatically recommend relevant learning partners to students' in order to form collaborative learning (Yang, \& Chen, 2008); also provides a channel for making friends. This feature can provide students to increase metacognition in a community college 
setting. In addition, it is not only showcasing their academic achievement, but also their creativity and interests.

- Dynamic resume: Extracts important and representative works from students' learning trees to form resumes; because new experiences can be continuously added into students' resume from the learning axis, it constructs a dynamic resume. This feature can provide learners with the learning process of self-learning and professional competence to develop.

- Learning axis: Records students' learning events in the form of a time axis, and combines students' learning process with the learning time, making it more helpful for observing students' growth. This feature can provide learners with the learning process of self-learning to develop.

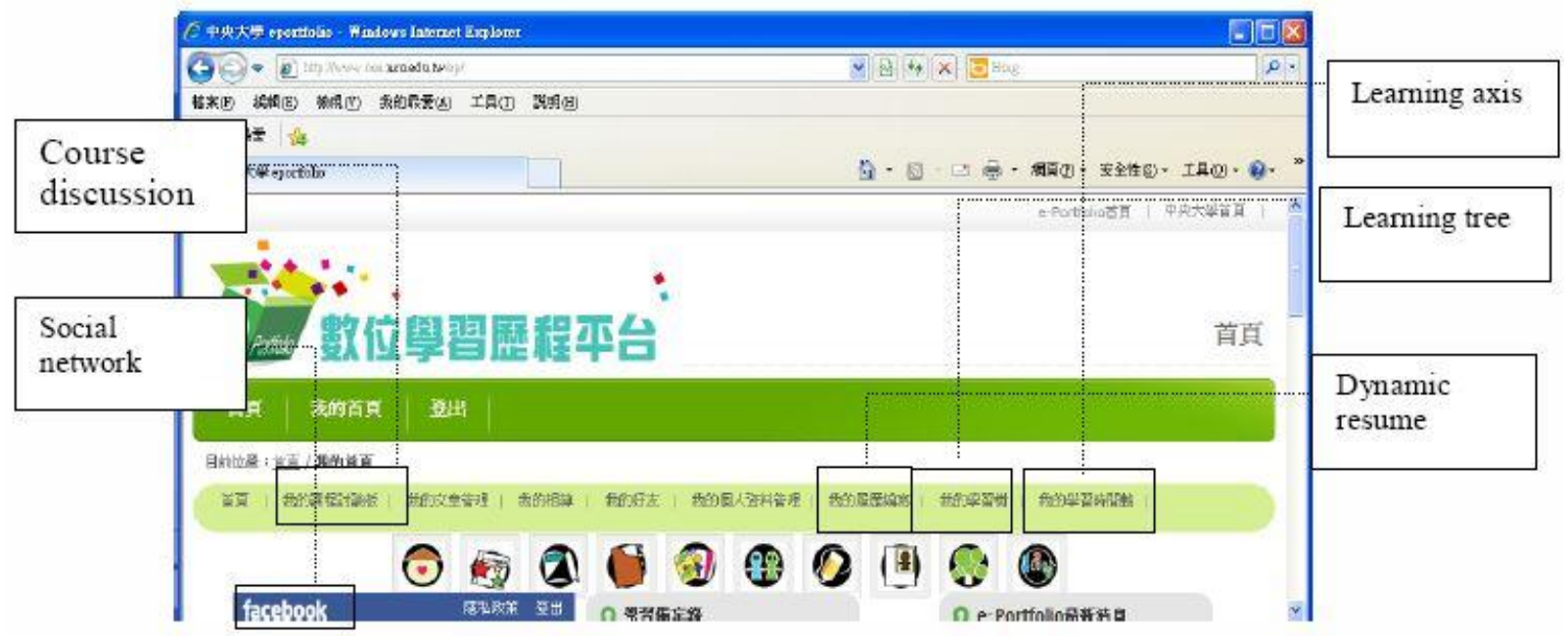

Fig. 2. e-Portfolio platform

\subsection{Learning activities}

Our experimental platform is on the e-Portfolio that in this experiment process is to allow students to use e-Portfolio functionality provided by the self-learning. Therefore, we design the e-Portfolio in the learning function to provide learning function such as learning tree, course discussion, social network, dynamic resume and learning axis functions. For the learning tree, it offers setting goals, learning process and sort out their own store. In term of the course discussion and Social network, it is emphasis on selfcorrection and reflection by group discussion and sharing to discover their blind spots. For the dynamic resume, it focus on the completion of milestones and through the learning axis to view in their own learning process throughout the learning stage each time put into effort and demonstration learning outcomes. Therefore, we are by this ePortfolio platform to record this series of learning activities, and then follow the questionnaire survey to observe the behavior of students, according to trend, trying to build out a study on e-Portfolio goal- oriented and metacognitive strategies model.

Based on Barrett's behavioral patterns of e-Portfolio (2007), this study designed a series of learning activities on e-Portfolio as follows: 
- Setting up learning goals: Learners list their learning goals or tasks and create files to form a learning tree.

- Collecting related resources: Learners collect learning materials based on their learning goals and add the collected resources to the learning tree.

- Reading and creative learning activities: Learners read the collected resources and write down what they have learned after reading the collected resources on ePortfolio. They construct their learning trees by putting their works on e-Portfolio.

- Reflections: Learners reexamined their works and make reflections.

- Reflections aroused by collective intelligence: Learners display their works to the public. Other learners read their works and discuss these works with them. Their thinking about their work expands through these discussions.

Achievement display: Learners display their achievements to the public.

\section{Data analysis and results}

We want to know the performance of students using e-Portfolio, such as mastery goals, performance-approach goals, and performance-avoidance goals. There is also an attempt to understand that the students in the e-Portfolio is the learning process helps students to develop metacognitive strategies, for example planning ahead and checking and correcting and so on. In addition, added enjoyment to understand the students in the learning process on whether the enjoyment in the e-Portfolio. Therefore, we use this ePortfolio platform for experiments, using SEM to build this model.

This study used SEM to analyze the hypotheses. Hair, Black, Babin, Anderson, and Tatham (2006), suggested a sample size between 100 and 400. Thus, this work considered 219 participants as valid. Additionally, this study used maximum likelihood estimation to acquire estimates of model parameters.

This research first estimated the measurement model to ensure the validity and reliability of the model. Secondly, the structural model examined the hypotheses between constructs proposed in the study.

\subsection{Measurement model}

Table 1 presents the correlation of latent variables, showing that the variables have a positive relationship with each other, except for the negative relation between performance-approach goals and metacognitive strategies. Table 2 presents descriptive statistics of constructs in the study. The findings indicate that students' scores on mastery goals, performance avoidance goals, metacognitive strategies, and enjoyment were over the mean scores, except for scores on performance approach goals The reliability of all constructs was respectively $.95, .95, .90, .91$, and .97 , which satisfied the criteria for reliability, over .70 (Nunnally, 1978).

Bandalos (2002), suggested that using item parcels contributed to better fitting solutions, and parceled solutions also resulted in less estimate bias of structural parameters than did solutions based on individual items. Thus, the study parceled mastery goals, performance approach goals, performance avoidance goals, and enjoyment into two indicators, shown in Table 3. For example, the items of enjoyment (EN) parceled into EN1 and EN2, as well as mastery goals (MG), performance approach goals (PAP), 
and performance avoidance goals (PAV). On the other hand, metacognitive strategies (MS) remained the same indicators, including planning ahead, content monitoring, planning during writing, and checking and correcting.

Table 1

The correlation of latent variables

\begin{tabular}{|c|c|c|c|c|c|}
\hline Variables & MAP & $\mathbf{P A P}$ & PAV & MS & $\mathbf{E N}$ \\
\hline 1. Mastery goals (MG) & - & & & & \\
\hline $\begin{array}{l}\text { 2. Performance-approach goals } \\
\text { (PAP) }\end{array}$ & $.524^{* *}$ & - & & & \\
\hline $\begin{array}{l}\text { 3. Performance-avoidance goals } \\
\text { (PAV) }\end{array}$ & $.534^{* *}$ & $.705^{* *}$ & - & & \\
\hline 4. Metacognitive strategies (MS) & $.594^{* *}$ & $-.308^{* *}$ & $.431^{* *}$ & 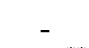 & \\
\hline 5. Enjoyment(EN) & $.735^{* *}$ & $.592^{* *}$ & $.537^{* *}$ & $.541^{* *}$ & - \\
\hline
\end{tabular}

Table 2

Descriptive statistics and reliability

\begin{tabular}{|c|c|c|c|c|}
\hline \multicolumn{2}{|l|}{ Constructs } & $\mathbf{M}$ & SD & $\begin{array}{c}\text { Reliability } \\
\text { (items) }\end{array}$ \\
\hline \multicolumn{2}{|l|}{ Mastery goals (MG) } & 4.24 & 1.25 & $.95(5)$ \\
\hline $\begin{array}{l}\text { Performance-approach } \\
\text { (PAP) }\end{array}$ & goals & 3.30 & 1.25 & $.95(5)$ \\
\hline $\begin{array}{l}\text { Performance-avoidance } \\
\text { (PAV) }\end{array}$ & goals & 3.69 & 1.18 & $.90(4)$ \\
\hline Metacognitive strategies & & 4.53 & 0.82 & $.91(14)$ \\
\hline Enjoyment(EN) & & 3.71 & 1.41 & $.97(3)$ \\
\hline
\end{tabular}

As Table 3 shows, except for two constructs, planning ahead and checking and correcting $(.59, .48)$, all factor loadings ranging from 0.74 to 0.96 were statistically significant and were larger than the criterion of 0.7 by Hair et al. (2006). This indicated that each item in the measurement model strongly related to its respective construct, since the respective latent constructs explained half or more of the variances in all the indicators. Although these two factors have low factor loadings, they are important factors of metacognitive strategies and cannot be removed. Thus, this study retained planning ahead and checking and correcting. Additionally, all composite reliability (CR) values ranging from 0.65 to 0.90 were higher than 0.6 , indicating a reliable measurement model. The average variance extracted (AVE) values ranged from 0.65 to 0.95 , which indicated a strong relation of each construct to its respective indicators. Overall, the measurement model exhibited adequate convergent validity. 
Table 3

Convergent validity for the measurement model

\begin{tabular}{cccc}
\hline Construct & Factor loading $^{\text {a }}$ & $\begin{array}{c}\text { Composite } \\
\text { reliability(CR) }\end{array}$ & $\begin{array}{c}\text { Average variance } \\
\text { extracted (AVE) }\end{array}$ \\
\hline MS & & .65 & .65 \\
planning ahead & .59 & & \\
content monitoring & .78 & & \\
planning during writing & .74 & & \\
checking and & .48 & .95 & .95 \\
correcting & & & \\
EN & & & \\
EN1 & .95 & .90 & \\
EN2 & .94 & & .89 \\
MG & & & \\
MG1 & .92 & .89 & \\
MG2 & .89 & & \\
PAP & & & \\
PAP1 & .82 & & \\
PAP2 & .96 & & \\
PAV & & & \\
PAV1 & .84 & & \\
PAV2 & .75 & & \\
& & & \\
\hline
\end{tabular}

\subsection{Structural model}

Table 4 shows a summary of the overall model fit measures. This study used a range of indices to evaluate the measurement model goodness-of-fit. While Hair et al. (2006) proposed that chi-square $\left(\chi^{2}\right)$ is the most important index to report, $\chi^{2}$ statistics are sensitive to the number of subjects. Therefore, it is improper to only use $\chi 2$ as the indicator of goodness-of-fit. Hair et al. (2006) added that researchers should report at least one absolute fit measure such as root mean square residual (RMSR), standardized root mean residual (SRMR), root mean square error of approximation (RMSEA), goodness-of-fit (GFI), and adjusted goodness-of-fit (AGFI).They should also report at least one incremental fit measure such as comparative fit index (CFI) and normed fit index (NFI)].

This study reports eight fit indices, indicating acceptable model fit: (1) the 2 2statistic; (2) the ratio 2 to the degrees of freedom ( $\chi 2$ /d.f.), with values of less than 3 indicating acceptable fit; (3) CFI, with values greater than 0.9 indicating acceptable fit; (4) RMSR, with values of less than 0.05 indicating acceptable fit; (5) SRMR, with values of less than 0.08 (with CFI of greater than 0.92) indicating acceptable fit; (6) RMSEA, with values of less than 0.07 (with CFI of 0.9 or higher) indicating acceptable fit; (7) GFI, with 
values greater than 0.9 indicating acceptable fit; and (8) AGFI, with values greater than 0.8 indicating acceptable fit (Wang \& Wang, 2009). Table 4 shows that assessing all measures, the full general structural model was accepted and believed to be good enough to analyze the parameter estimates.

Table 4

Goodness-of-fit measurement for SEM

\begin{tabular}{lll}
\hline Fit measures & Values & Criteria \\
\hline$\chi^{2}$ & $85.86(p=.00)$ & $p<.05$ \\
$\chi^{2} / d f$ & 1.95 & $<3$ \\
CFI & .99 & $>.90$ \\
RMSR & .05 & $<.05$ \\
SRMR & .05 & $<.08$ \\
RMSEA & .06 & $<.07$ \\
GFI & .94 & $>.90$ \\
AGFI & .90 & $>.80$ \\
\hline
\end{tabular}

Table 5 summarizes the parameter estimates for the hypothesized paths, their $\mathrm{t}$ values, and the hypotheses results. From Table 5, the direct effect of all hypothesized paths is significant, except the path from performance avoidance goals to enjoyment. As for indirect effect, only mastery goals can significantly predict metacognitive strategies among indirect effect of three paths.

Table 5

Effects of variables and results of hypotheses

\begin{tabular}{lcccccc}
\hline $\begin{array}{c}\text { Hypothesized } \\
\text { path }\end{array}$ & \multicolumn{3}{c}{ Standardized estimate } & \multicolumn{2}{c}{ Result of hypotheses } \\
\hline & $\begin{array}{c}\text { Direct } \\
\text { effect }\end{array}$ & $\begin{array}{l}(\mathrm{t} \text {-value }) \\
\text { Indirect } \\
\text { effect }\end{array}$ & $\begin{array}{c}(\mathrm{t}- \\
\text { value) }\end{array}$ & $\begin{array}{c}\text { Total } \\
\text { effect }\end{array}$ & \\
$\mathrm{MG} \rightarrow \mathrm{MS}\left(\mathrm{H}_{1}\right)$ & .50 & $\left(5.20^{*}\right)$ & .13 & $\left(2.32^{*}\right)$ & .63 & Supported \\
$\mathrm{PAP} \rightarrow \mathrm{MS}\left(\mathrm{H}_{2}\right)$ & -.42 & $\left(-3.81^{*}\right)$ & .06 & $(1.86)$ & -.36 & Supported \\
$\mathrm{PAV} \rightarrow \mathrm{MS}\left(\mathrm{H}_{3}\right)$ & .37 & $\left(3.33^{*}\right)$ & .00 & $(0.07)$ & .37 & Supported \\
$\mathrm{MG} \rightarrow \mathrm{EN}\left(\mathrm{H}_{4}\right)$ & .59 & $\left(10.05^{*}\right)$ & & & .59 & Supported \\
$\mathrm{PAP} \rightarrow \mathrm{EN}\left(\mathrm{H}_{5}\right)$ & .28 & $\left(3.42^{*}\right)$ & & & .28 & Supported \\
$\mathrm{PAV} \rightarrow \mathrm{EN}\left(\mathrm{H}_{6}\right)$ & .01 & $(0.07)$ & & & .01 & Not supported \\
$\mathrm{EN} \rightarrow \mathrm{MS}\left(\mathrm{H}_{7}\right)$ & .22 & $\left(2.36^{*}\right)$ & & & .22 & Supported \\
\hline
\end{tabular}

Fig. 3 shows that the model developed in this study supported hypothesis H1, H2, $\mathrm{H} 3, \mathrm{H} 4, \mathrm{H} 5$, and H7. All the relationships among the constructs were significant, except the relationship between performance avoidance goals and enjoyment. The result of the study demonstrated that the motivation model supported six out of seven hypotheses.

Relating to the direct effects between the constructs, enjoyment, one endogenous construct of the study, was positively predicted by mastery goals $(\mathrm{H} 4=.59)$ and performance approach goals $(\mathrm{H} 5=.28)$. Mastery goals positively predicted the other endogenous construct, metacognitive strategies, $(\mathrm{H} 1=.50)$, performance avoidance goals $(\mathrm{H} 3=.37)$, and enjoyment $(\mathrm{H} 7=.22)$, and performance approach goals negatively 
predicted metacognitive strategies $(\mathrm{H} 2=-.42)$. Regarding indirect effects, only mastery approach goals can indirectly and positively predict metacognitive strategies through enjoyment $(\mathrm{t}=2.32)$. Findings showed the strongest magnitude in a relationship between mastery approach goals and metacognitive strategies, followed by the relationship between mastery goals and enjoyment.

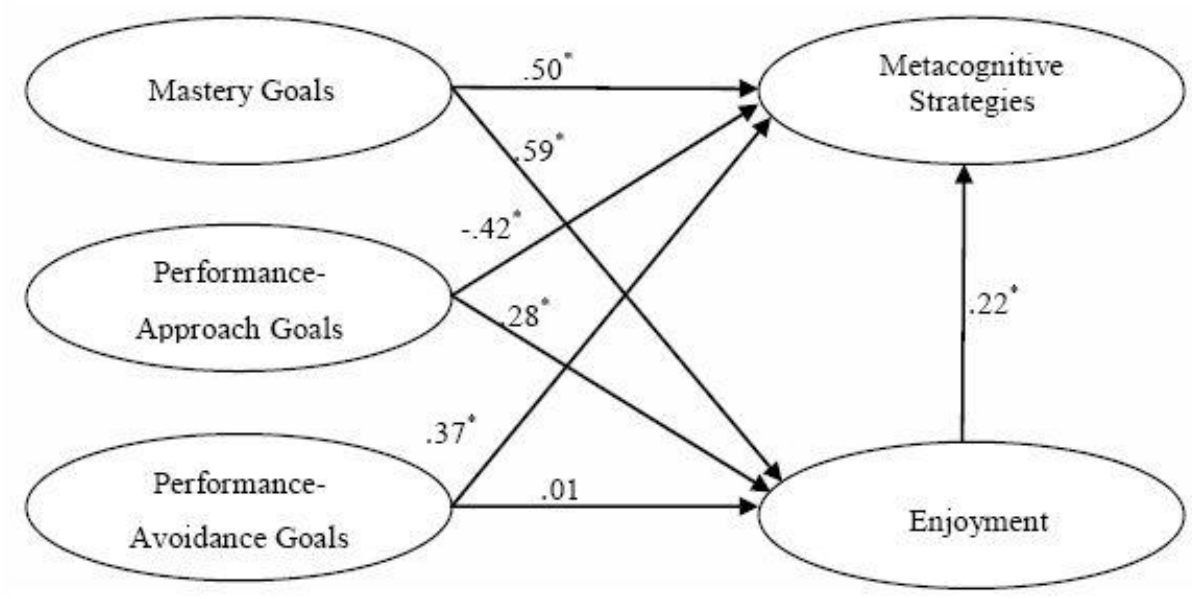

Fig. 3. Parameter estimates of general structural model $\left({ }^{*} \mathrm{p}<.05\right)$

\section{Discussion}

The present research leads to the conclusion that the model represented the collected data well according to the goodness-of-fit test result. Among three goal orientations, mastery goals are seemingly the most adaptive goal orientation for students using e-Portfolio. This result is consistent with previous studies conducted in the traditional classroom. The outcome is possibly because mastery goals refer to orientation engagement toward increasing competence (Dweck, 1986), and students adopting mastery goals are likely to demonstrate a positive attitude towards learning, challenging work, and deeper processing strategies for learning. Students who believed the e-Portfolio course was interesting, important, and useful, reported using more learning strategies. Therefore, mastery goals not only positively predict both enjoyment and metacognitive strategies to some extent, but also indirectly predict metacognitive strategies through enjoyment. That is, students with higher mastery goals may be more adaptive in the e-Portfolio course, acquire more enjoyment, and more likely to use metacognitive strategies to improve self learning process and learning outcome.

Mastery goals and performance approach goals also positively predicted enjoyment. The result is similar to the findings by Pekrun (2006). Namely, mastery goals and performance approach goals both can facilitate positive outcome emotions like enjoyment. This research infers that students with performance approach goals feel more enjoyment using e-Portfolio, which provides them with a social network to not only showcase their academic achievement, but also their creativity and interests. Performance avoidance goals in the study, however, failed to negatively predict enjoyment, unlike the result found by Pekrun (2006) that performance avoidance goals should easily evoke negative outcome emotions and negatively predict positive outcome emotions. 
Surprisingly, unlike previous researches, performance-avoidance goals in this study can positively predict metacognitive strategies and can not predict enjoyment. This result may be due to using e-Portfolio. Because the use of e-Portfolio for those performance avoidance learner to provide thinking and practice space to learning how to use of metacognitive strategies. Moreover, in the past research indicates that the relationship between e-Portfolio and metacognitive strategies is positive (Azevedo, 2005; Zellers \& Mudrey, 2007). Zellers and Mudrey (2007) indicate that e-portfolios can be an effective platform for students to increase metacognition in a community college setting. Chang \& Peng (2008) found that the e-Portfolio system had no effect on academic achievement for students with the highest and lowest levels of motivation. However, it was more effective on self-perceived effect for low motivation students. E-Portfolio helps low motivation students organize, construct, and reflect on their learning process or observe peers' collections, forcing them to construct their learning through exterior guidance. Wolters (2004) concluded that studies involving college students did not separate approach and avoidance goals, and failed to find clear evidence connecting students' performance goals and metacognitive strategies. The uncommon results, therefore, need future researches to explore the relationship among performance avoidance goals, enjoyment, and metacognitive strategies.

\section{Conclusion and future research}

This study develops an integrated model to interpret and predict students' goal orientation, metacognitive strategies, and enjoyment in the context of using e-Portfolio, and uses structural equation modeling for examining the proposed model. The findings support the model we present. Six of the seven hypotheses are significant, contributing to the realization about the process of students' learning with respect to motivation, positive emotion, and learning strategies.

Several findings are concluded from the current study: (1) we found that students' mastery goals, when using e-Portfolio, have a positive effect on their metacognitive strategies and enjoyment.; (2) For performance-approach goals have a negative effect on metacognitive strategies and have a positive effect on enjoyment; (3) For performanceavoidance goals have a positive effect on metacognitive strategies; (4) students' enjoyment has a positive effect on their metacognitive strategies and mastery goals can predict metacognitive strategies through enjoyment.

The findings in this study have some educational implications for e-Portfolio learning as following lists:

As (1) revealed in this study, the mastery goals students in the traditional classroom learning behaviors and the context in the use of e-Portfolios are all adaptive. In other words, the mastery goals students will feel the pleasure to learn and to use variety metacognitive strategies when use of e-Portfolios in the context. Therefore, the ePortfolio can help students to develop variety metacognitive strategies.

As (2) revealed in this study, the performance-approach goals students is less proficient use of metacognitive strategies. Therefore, students should be guided by teachers interventions and training use of variety metacognitive strategies in their learning such as setting goals, planning ahead, checking and correcting.

As (3) revealed in this study, the results represent that the e-Portfolio platform will help these students to use of variety metacognitive strategies who have performance- 
avoidance goals. Therefore, the teacher should encourage students to use the e-Portfolio platform.

As (4) revealed in this study, the results indicated that e-Portfolio can provide students with a more stress-free learning space. In the e-Portfolio learning space will help students to develop variety metacognitive strategies and setting goals abilities.

This study has a few limitations. First, students in the study filled out the questionnaire after eight weeks of using e-Portfolio. Their responses may be affected because they did not use e-Portfolio long enough to fully discuss the learning materials with peers, carefully observe others' process of knowledge construction, and critically reflect their learning. The self-reporting questionnaire does not easily address the use of metacognitive strategies, and students may overestimate their ability to manipulate metacognitive strategies.

The proposed model requires further research to test thoroughly. We briefly outline three suggestions for future research. First, use more correlation and experimental studies to assess how adopted personal goal orientations influence emotion and learning strategies in the context of e-Portfolio. Second, because most of the reviewed researches used self-reported measures of enjoyment, we suggest future studies employ a variety of methodologies (e.g. records of the interaction with peers and content of the text in ePortfolio) to assess specific emotions and clarify the understanding of how goal orientations relate to various emotions in the course using e-Portfolio. Third, make sure students are familiar with the interface of e-Portfolio and have sufficient technology skills to manipulate e-Portfolio, or e-Portfolio will be a barrier to academic performance. Finally, this study only explores personal variables. We suggest future research emphasize the contextual features of the learning environment and subsume the variables regarding contexts (e.g. classroom goal structures and social goals) to enhance understanding about the influence of students' perceived environment.

\section{Acknowledgement}

This work is supported by National Science Council, Taiwan under grants NSC98-2511S-008-006-MY3 and NSC98-2511-S-008-007-MY3 and NSC 100-2511-S-146 -001.

\section{References}

Abrami, P. C., \& Barrett, H. (2005). Directions for research and development on electronic portfolios. Canadian Journal of Learning and Technology, 31(3), 1-6.

Artino, A. R. (2009). Think, feel, act: motivational and emotional influences on military students' online academic success. Journal of Computing in Higher Education, 21, $146-166$.

Azevedo, R. (2005). Using hypermedia as a metacognitive tool for enhancing student learning? The role of self-regulated learning. Educational Psychologist, 40, 199-209.

Bandalos, D. L. (2002). The effects of item parceling on goodness-of-fit and parameter estimate bias in structural equation modeling. Structural Equation Modeling, 9(1), $78-102$.

Barrett, H., \& Knezek, D. (2003). E-portfolios: Issues in assessment, accountability and preservice teacher preparation. Paper presented at the American Educational Research Association Conference, Chicago, IL. 
Barrett, H. C. (2007). Researching electronic portfolios and learner engagement: The REFLECT initiative. Journal of Adolescent \& Adult Literacy, 50(6), 436-449.

Bartels, J. M., \& Magun-Jackson, S. (2009). Approach-avoidance motivation and metacognitive self-regulation: The role of need for achievement and fear of failure. Learning and Individual Differences, 19(4), 459-463.

Bekele, T. A. (2010). Motivation and satisfaction in internet-supported learning environments: A review. Educational Technology \& Society, 13(2), 116-127.

Blackburn, J. L., \& Hakel, M. D. (2006). Enhancing self-regulation and goal orientation with e-Portfolio. In A. Jafari \& C. Kaufman (Eds.), Handbook of Research on ePortfolio ( chap. 9, pp. 83-89). Hershey PA: Idea Group Reference.

Chang, C. C., \& Peng, S. R. (2008).Use and effects of web-based portfolio assessment on computer course of junior high schools. Journal of National Taiwan Normal University: Mathematics \& Science Education, 53(2), 31-57.

Davis, F. D., Bagozzi, R. P., \& Warshaw, P. R. (1992). Extrinsic and intrinsic motivation to use computers in the workplace. Journal of Applied Social Psychology, 22, 11111132.

Dweck, C. S. (1986). Motivational processes affecting learning. American Psychologist, $41,1040-1048$.

Elliot, A. J., \& Church, M. A. (1997). A hierarchical model of approach and avoidance achievement motivation. Journal of Personality and Social Psychology, 72, 218-232.

Elliot, A. J., \& McGregor, H. A. (2001). A $2 \times 2$ achievement goal framework. Journal of Personality and Social Psychology, 80(3), 501-519.

Hair, J. F. Jr., Black, W. C., Babin, B. J., Anderson, R. E., \& Tatham, R. L. (2006). Basics of structural equation modeling. Thousand Oaks, CA: Sage.

Herner-Patnode, L. M., \& Lee, H.-J. (2009). A capstone experience for preservice teachers: Building a web-based portfolio. Educational Technology \& Society, 12(2), 101-110.

Hou, M. J. (2002). The effects of multiple goal orientations on junior high school students' cognition, motivation, affect and learning behavior. Unpublished master's thesis, University of Cheng Kung, Taiwan.

Kaplan, A., Lichtinger, E., \& Gorodetsky, M. (2009). Achievement goal orientations and self-regulation in writing: An integrative perspective. Journal of Educational Psychology, 101 (1), 51-69.

Lichtinger, E., Kaplan, A., \& Gorodetsky, M. (2006, September). Exploring selfregulation in writing among junior high-school students: A stimulated recalls study. Paper presented at the 10th International Conference of the EARLI Special Interest Group on Writing, Antwerp, Belgium.

Linnenbrink, E. A. (2005). The dilemma of performance-approach goals: The use of multiple goal contexts to promote students' motivation and learning. Journal of Educational Psychology, 97(2), 197-213.

Linnenbrink, E. A., \& Pintrich, P. R. (2002). Achievement goal theory and affect: An asymmetrical bidirectional model. Educational Psychologist, 37(2), 69-78.

Lopez-Fernandez, O., \& Rodriguez-Illera, J. L. (2009). Investigating university students' adaptation to a digital learner course portfolio. Computers \& Education, 52(2), 608616.

Matuga, J. M. (2009). Self-regulation, goal orientation, and academic achievement of secondary students in online university courses. Educational Technology \& Society, $12(3), 4-11$.

Meyer, E., Abrami, P. C., Wade, C. A., Aslan, O., \& Deault, L. (2010). Improving literacy and metacognition with electronic portfolios: Teaching and learning with ePEARL. Computers \& Education, 55(1), 84-91.

Midgley, C., Kaplan, A., \& Middleton, M. (2001). Performance-approach goals: Good 
for what, good for whom, under what circumstances, and at what cost? Journal of Educational Psychology, 93, 77-86.

Midgley, C., Maehr, M. L., Hruda, L. Z., Anderman, E., Anderman, L., Freeman, K. E., Gheen, M., Kaplan, A., Kumar, R., Middleton, M. J., Nelson, J., Roeser, R., \& Urdan, T. (2000). Manual for the patterns of adaptive learning scales (PALS). Ann Arbor, MI:University of Michigan.

Midgley, C., \& Urdan, T. (2001). Academic self-handicapping and achievement goal: A further examination. Contemporary Educational Psychology, 26, 61-75.

Nunnally, J. C. (1978). Psychometric theory. New York, NY: McGraw-Hill.

Pekrun, R. (2005). Progress and open problems in educational emotion research. Learning and Instruction, 15, 497-506.

Pekrun, R. (2006). The control-value theory of achievement emotions: Assumptions, corollaries, and implications for educational research and practice. Educational Psychology Review, 18, 315-341.

Pekrun, R., Elliot, A. J., \& Maier, M. A. (2009) Achievement goals and achievement emotions: Testing a model of their joint relations with academic performance. Journal of Educational Psychology, 101(1), 115-135.

Pekrun, R., Goetz, T., Titz, W., \& Perry, R. P. (2002). Academic emotions in students' self-regulated learning and achievement: A program of quantitative and qualitative research. Educational Psychologist, 7, 91-106.

Pintrich, P. R. (1999) .The role of motivation in promoting and sustaining self-regulated learning. International Journal of Educational Research, 31, 459-470.

Pintrich, P. R. (2000). An achievement goal theory perspective on issues in motivation terminology, theory, and research. Contemporary Educational Psychology, 25, 92104.

Sahin, I., \& Shelley, M. (2008). Considering students' perceptions: The distance education student satisfaction model. Educational Technology \& Society, 11(3), 216223.

Shen, L., Wang, M., \& Shen, R. (2009). Affective e-learning: Using "emotional" data to improve learning in pervasive learning environment. Educational Technology \& Society, 12 (2), 176-189.

Sperling, R. A., Howard, B. C., Staley, R., \& DuBois, N. (2004). Metacognition and selfregulated learning constructs. Educational Research and Evaluation, 10, 117-139.

Su, A. Y. S., Yang, S. J. H., Hwang, W. Y., Zhang, J. (2010). A Web 2.0-based collaborative annotation system for enhancing knowledge sharing in collaborative learning environments. Computers \& Education, 55(2), 752-766

Tsai, M.-J. (2009). The model of strategic e-learning: Understanding and evaluating student e-learning from metacognitive perspectives. Educational Technology \& Society, 12 (1), 34-48.

Urdan, T. (2004). Predictors of academic self-handicapping and achievement: Examining achievement goals, classroom goal structures, and culture. Journal of Educational Psychology. 96(2), 251-264.

Vrugt, A., \& Oort, F. J. (2008). Metacognition, achievement goals, study strategies and academic achievement: Pathways to achievement. Metacognition and Learning , 30, 123-146.

Wade, A., Abrami, P. C., \& Sclater, J. (2005). An electronic portfolio to support learning. Canadian Journal of Learning and Technology, 31(3), 33-50.

Walz, P. (2006). An overview of student e-portfolio functions. In A. Jafari \& C. Kaufman, Handbook of Research on ePortfolio (chap. 19, pp. 194-204). London: Idea Group Reference.

Wang, W. T., \& Wang, C. C. (2009). An empirical study of instructor adoption of web- 
based learning systems. Computers \& Education, 53(3), 761-774.

Wickersham, L. E., \& Chambers, S. M. (2006). e-Portfolio: Using technology to enhance and assess student learning. Education, 126(4), 738-746.

Witkow, M. R., \& Fuligni, A. J. (2007). Achievement goals and daily school experiences among adolescents with Asian, Latino, and European American backgrounds. Journal of Educational Psychology, 999(3), 584-596.

Wolters, C. A. (2004). Advancing achievement goal theory: using goals structures and goal orientations to predict students' motivation, cognition and achievement. Journal of Educational Psychology, 96, 236-250.

Yi, M. Y., \& Hwang, Y. (2003). Predicting the use of web-based information systems: Self-efficacy, enjoyment, learning goal orientation, and the technology acceptance model. International Journal of Human-Computer Studies, 59, 431-449.

Yang, S. J. H., Chen, I. Y. L. (2008). A social network-based system for supporting interactive collaboration in knowledge sharing over peer-to-peer network. International Journal of Human-Computer Studies, 66(1). 36-50

Zellers, M., \& Mudrey, R. (2007). Electronic portfolios and metacognition: A phenomenological examination of the implementation of e-portfolio from the instructors' perspective. International Journal of Instructional Media, 34(4), 419-430.

Zimmerman, B. J. (2000). Attaining self-regulation: a social cognitive perspective. In M. Boekaerts \& P. R. Pintrich (Eds.), Handbook of Self-Regulation (pp. 13-39). New York: Academic Press.

Zimmerman, B. J. (2001). Theories of self-regulated learning and academic achievement: An overview and analysis. In B. J. Zimmerman \& D. H. Schunk (Eds.), SelfRegulated Learning and Academic Achievement: Theoretical Perspectives (2nd ed.) (pp. 1-37). Mahwah, NJ: Lawrence Erlbaum. 